\title{
Sexual orientation discrimination in the labour market ${ }^{\text {ts }}$
}

\author{
Nick Drydakis * \\ Department of Economics, University of Piraeus, 80 Karaoli and Dimitriou Street, 18534 Piraeus, Greece \\ Department of Regional Economic Development, University of Central Greece, 8 L. Katsoni Street, 32100 Levadia, Greece \\ Department of Public Administration, Panteion University of Social and Political Sciences, 136 Syggrou Avenue, 17671, Kallithea, Athens, Greece \\ Scientific Centre for the Study of Discrimination, Ioov, Athens, Greece
}

\section{A R T I C L E I N F O}

\section{Article history:}

Received 6 December 2007

Received in revised form 4 November 2008

Accepted 16 December 2008

Available online 3 January 2009

JEL classification:

C93

J7

J16

J31

J42

J64

J71

$\mathrm{J} 82$

Keywords:

Field experiment

Sexual orientation

Hiring discrimination

Wage discrimination

Probit model

OLS model

\begin{abstract}
A B S T R A C T
This research examines the possible discrimination faced by gay men compared to heterosexuals when applying for jobs in the Greek private sector. This issue was addressed through the observation of employer hiring decisions. Mailing pairs of curriculum vitae, distinguished only by the sexual orientation of the applicants, led to the observation that gay men faced a significantly lower chance of receiving an invitation for an interview. However, in cases where employers called applicants back, the wages offered did not differ significantly between gay and heterosexual applicants. Nevertheless, there is substantial evidence to suggest that discrimination based on sexual orientation does exist in the Greek labour market, and at alarmingly high levels.
\end{abstract}

(c) 2009 Elsevier B.V. All rights reserved.

\section{Introduction}

During the past several decades, gay and lesbian Greeks have been fighting for visibility, equal rights and respect with limited success (Peponas, 2004). Despite the significant amount of public policy debate underway, it is apparent that sexual minority individuals are still facing unfair treatment in significant areas of their lives. In particular, the lack of legal recognition of family structures, the persistence of threats, the perpetuation of false stereotypes, and the lack of political will shown by the authorities in the fight against discrimination are the demonstrations of such attitudes (Vlami, 2007; Petropoulou and Skoutari, 2008).

\footnotetext{
it I am grateful to the co-editor Ian Walker. I acknowledge assistance from two anonymous referees whose comments and suggestions have significantly contributed to the improvement of previous versions of this paper. Funding from the Scientific Centre for the study of Discrimination is gratefully acknowledged.

* Department of Economics, University of Piraeus, 80 Karaoli and Dimitriou Street, 18534 Piraeus, Greece.

E-mail address: ndrydakis@econ.soc.uoc.gr.
}

Historical, sociological, and psychological research demonstrate the existence of homophobia, heterosexism and sexual prejudice ${ }^{1}$ and the effects that such attitudes have in everyday experiences of gays and lesbians. However, economists have only recently explored the relationship between labour market outcomes and sexual orientation. Briefly, wage regressions have documented lower incomes for gays, but they have repeatedly shown higher incomes for lesbians. Most studies

\footnotetext{
${ }^{1}$ Following Weinberg (1972), the term homophobia is used to label heterosexuals' dread of being in close quarters with homosexuals as well as homosexuals' selfloathing. In general, distastes and phobia focus on homosexual peoples' behaviour lifestyle and culture. Heterosexism is used as a term analogous to sexism and racism, describing an ideological system that denies, denigrates, and stigmatises any nonheterosexual form of behaviour, identity, relationship, or community (Herek 1990). The term highlights the parallels between antigay sentiment and other forms of prejudice, such as racism, anti-Semitism, and sexism. Sexual prejudice refers to all negative attitudes based on sexual orientation, whether the target is homosexual, bisexual or heterosexual. The prejudice is almost always directed at people who engage in homosexual behaviour or label themselves gay, lesbian, or bisexual (Herek 2000).
} 
seem to agree that discrimination ${ }^{2}$ is the dominating mechanism that explains earnings gaps. However, wage gaps are only one of the possible forms that discrimination can take. Labour legislation, for instance, focuses more frequently on discrimination in hiring and harassment.

According to Becker (1993), a taste for discrimination among profit-maximizing employers, employees or customers is a prerequisite for discrimination in the labour market. Given the widely cited prevalence of homophobia in Greek society, ${ }^{3}$ it seems likely that sexual minority individuals experience discrimination in the labour market. Similarly, sexual minority individuals throughout Europe have repeatedly claimed that they are fired, not hired, or not promoted because of their orientation (De Schutter, 2008). Those incidents have indicated to many policymakers that racism and other forms of discrimination could jeopardise the European Community's aims of full market integration and social cohesion. Recently, legislators have moved towards a public policy dictating that the labour market treatment of individuals should be based on their productivity rather than on their sexual orientation. New laws prohibiting discrimination on the grounds of sexual orientation (2005/3304) came into force on January 2005 under the European Union's Employment Equality (Sexual Orientation) Directive 2000/78. According to this legislation, employment equality applies to everyone regardless of their sexual orientation. ${ }^{4}$

Notably, in Greece, there are no sample sizes of the sexual orientation of individuals for investigation of the discrimination hypothesis. However, empirical research examining where wage differentials exist, although highly interesting, cannot provide information about labour market discrimination against equally productive gay workers. More importantly, disclosure or labeling of a gay employee's sexual orientation is necessary, otherwise the practice of hiding one's sexual preference is likely to reduce the measurable impact of discriminatory behavior. Hence, an accurately measured signal of sexual orientation is crucial for credibly testing the discrimination hypothesis.

This study takes a different route to assess differential treatment against gay men by using an experimental technique to gather representative data on the labour market outcomes of gay men. Job applications of candidates who were equivalent in their human capital but differed only in their sexual orientation were sent out in response to job advertisements. Methodologically, following Adam (1981) and Weichselbaumer (2003), a gay applicant's sexual orientation was labeled through a reference in his curriculum vitae to voluntary work at a homosexual community organization. The methodology implied that the signal was accurate for credibly testing the discrimination hypothesis. The theoretical claim to be evaluated was that an applicant who was an activist in such a community might receive biased evaluations of his skills and profitability, diminishing hiring chances (Seidman, 1994).

In particular, by means of correspondence testing, we aimed to detect sexual orientation discrimination in the preliminary stage of the selection process, which for gays seems to be a crucial barrier to

\footnotetext{
${ }^{2}$ Labour market discrimination exists when two equally qualified individuals are treated differently in the labour market on the basis of some personal characteristic unrelated to productivity (Arrow, 1973). Discrimination can take the form of differences in earnings or differences in hiring and promotion practices (Clain and Leppel, 2001).

${ }^{3}$ Greece is one of the most puritan societies when it comes to general attitudes towards homosexuality. Eurobarometer (2007/263) reveals that the wide majority of Greeks (85\%) feel that homosexuality is a taboo, compared to $48 \%$ of European Union individuals, while the wide majority $(84 \%)$ share the opinion that it is difficult for gay and lesbians to state their sexual orientation at work, compared to $68 \%$ of European Union respondents.

${ }^{4}$ It is unlawful to discriminate against: (i) job applicants - in relation to recruitment, arrangements, decisions, and harassment, (ii) employees - in relation to terms, promotions, transfers, training, benefits, and dismissals, (iii) ex-employees - where the discrimination is closely connected to their employment.
}

the labour market (Eurobarometer, 2007). The selection processes are very often not guided by standards, while the standards themselves might lead to the exclusion of certain members of minority groups from obtaining a specific job. Interestingly, in this study, we also examined whether sexual orientation affected wages at the beginning of working careers. By taking advantage of telephone callbacks, we have extended the application of this method by also gathering data concerning informal wage offers on the part of employers in cases of tentative hiring. We argue that this additional data set enabled us to further record discriminatory attitudes across sexual orientations in the ensuing steps of the hiring process. ${ }^{5}$

A crucial benefit of the correspondence test is that it offered a chance to examine an important aspect of labour market discrimination in hiring that has been largely inaccessible to social scientists. Because of the absence of standardised, economy-wide data on hiring, there is much less evidence on discrimination in these important dimensions of labour market discrimination. Too often, gays and lesbians live with harassment and discriminatory practices, thinking that this is normal. In addition, very few employers understand what constitutes sexual orientation discrimination in employment. The systematic study of sexual minority individuals is valuable for both its policy relevance and its potential to inform social scientists about the functioning of the labour market.

Despite the introduction of antidiscrimination legislation 3 years ago, the current results showed a strong negative effect of gay orientation on hiring chances. On the other hand, sexual orientation did not have a significant impact on the wages offered. This research contributes to the small but growing body of literature on the economics of discrimination according to sexual orientation by presenting an assessment of the impact of this antidiscrimination legislation. In addition to providing evidence on sexual orientation based differences in economic outcomes for a previously unstudied country, this research advances the literature in several ways. Our measure of sexual orientation is likely to be correlated with the concept of interest and living an openly gay lifestyle, and it is arguably better that the sexual behavior measures used in previous research. ${ }^{6}$ The wage differential estimated in this paper was computed taking into account the employer's knowledge of the employee's orientation. In the current study, we reconsidered whether discriminatory treatments existed in cases where the evidence seemed strongest: the various penalties for gay-labeled men.

The paper is organized as followed: Section 2 provides a brief review of the existing literature on sexual orientation and economic outcomes. Section 3 describes the methodology, and Section 4 presents the estimation framework. Section 5 presents the main results and offers a discussion, and the last section concludes the paper.

\section{Literature review}

While there have been numerous economic studies of race and sex discrimination, the issue of discrimination on the basis of sexual orientation has been largely neglected. Only recently has there been a growing interest in understanding the relationship between sexual orientation and earnings as it relates to evaluating the possibility of labour market discrimination. Previous research on the wage gap between gay and straight workers suggests that gay men are paid less than similarly qualified straight men, but it indicates that there is a great deal of variation in the estimates of the difference in earnings between lesbians and heterosexual women.

\footnotetext{
${ }^{5}$ Following Adam (1981), we assumed that interview offers by employers were indicative of their willingness to consider applicants employable.

${ }^{6}$ Shortcomings include potential selection bias, the absence of information on the extent to which gays reveal their sexual orientation in the workplace, and the exclusion of observations of single homosexuals as opposed to homosexual couples.
} 
A number of studies have documented a significant and dramatic relationship between sexual orientation and economic outcomes in the United States. Badgett (1995), using data from the 1989-91 General Social Survey (GSS), found that gay men earned 28\% less than heterosexual men and that lesbians earned 35\% less than heterosexual women. Black et al. (2003) employed GSS data from 1989-96 and found earnings to be between $14 \%$ and $16 \%$ lower for gay men than for heterosexuals and between $20 \%$ and 34\% higher for lesbian women than for heterosexuals. Moreover, Carpenter (2007) used the Third National Health and Nutrition Examination Survey from the 1984-94 wave and found that gay men experienced a statistically and economically significant penalty on the order of $23-30 \%$. Allegretto and Arthur (2001) used data from the 1990 Census on men and found a smaller gay male earnings penalty on the order of 3\%. Furthermore, Carpenter (2005) used data from a public health survey in California (California Health Interview Survey) and found small statistically insignificant earnings differentials for gay men and lesbians compared to heterosexuals. Similarly, studies of men in the Netherlands found small effects (Plug and Berkhout, 2004). In the United Kingdom, Arabsheibani et al. (2004), using data from the Labour Force Survey between 2001 and 2005, found that gay men earned about 5\% less than heterosexuals, while lesbians earned about $9 \%$ more than heterosexual women.

Only two field experiments have been carried out to test sexual orientation in the hiring process. Weichselbaumer (2003) employed a field experiment in order to investigate whether the Austrian labour market discriminated against lesbian women. She found that indicating a lesbian identity reduced the invitation rate by about $12-13 \%$. Moreover, Adam (1981) used a similar technique for testing discrimination based on sexual orientation and found a reduction of $6 \%$ in invitation rates for lesbians and $7 \%$ for gays in the city of Toronto in Ontario, Canada. Both studies agreed that discrimination could explain the differences in hiring.

The evidence of earnings effects of sexual orientation has garnered a variety of economic explanations for the source of such differences. One explanation for the observed wage differential between heterosexuals and homosexuals is that employers discriminate against sexual minority individuals (Becker, 1957; Arrow, 1973). However, arguing that the effect of sexual orientation on earnings by sex is inconsistent with the sexual orientation-based discrimination theories, researchers have sought explanations elsewhere. Some have invoked the hypothesis that sexual minority individuals are paid differently than heterosexuals because they do not conform to traditional gender roles (Blandford, 2003). However, other explanations for the wage differentials are possible. In the economic story of specialisation, expectation of marriage and acceptance of traditional gender roles drive the relationship between sexual orientation and earnings (Becker, 1991). Other theories argue that gay men and lesbians choose different levels of work effort given different budget constraints (Berg and Donald, 2002). However, additional unobservable factors may have contributed to the wage gap.

\section{Design of the experiment}

\subsection{Correspondence test}

The correspondence test approach, so named for its simulation of the communication between job applicants and employers, involves sending carefully matched pairs of written job applications in response to advertised vacancies to test for discrimination in labour hiring at the initial stage of selection for interview. The correspondence test is a form of social experiment in a real life situation that has the potential to provide statistical data on discriminatory treatments. The methodology provides a unique opportunity to conduct tests because it highlights the circumstances under which unequal treatments occur and provides a powerful means of isolating causal mechanisms.
Following Riach and Rich (2002), in correspondence testing, at least two individuals are matched for all relevant characteristics other than the one that is expected to lead to discrimination. The pseudoseekers are typically matched on such attributes as age, education, experiences and marital status. The goal is to produce pairs of testers who are identical in all relevant characteristics so that any systematic difference in treatment within each pair can be attributed only to the effects of the group characteristic. Reactions from employers are then typically measured by written responses or callbacks. Correspondence test analysts assume that they know which characteristics are relevant to employers and when such characteristics are sufficiently close to make majority and minority applicants indistinguishable. Hence, applicants must be matched on each of the relevant characteristics.

\subsection{Gay labeling}

Homosexuality is a status characteristic that, when salient, results in biased evaluations of competence. ${ }^{7}$ Once the status becomes evident to employers, applicants become labeled as outsiders, and expectations and assumptions are associated with the individuals, such as expectations about the way other people will respond to these individuals. Psychological and sociological studies suggest that gay men try to avoid discrimination by living a dual life at work (Levine and Leonard, 1984). On the labour market, they pass for non-gay for fear that their employment would be in jeopardy if it became known that they were gay, while outside the labour market, they come out. ${ }^{8}$ Unlike ethnic and racial minorities, the disabled and the elderly, who are vulnerable to discrimination and harassment, gay men may be said to be in the "best position" in this regard since they can avoid discrimination by hiding their sexual orientation. In other words, disclosure of sexual orientation is a decision involving a trade-off between disclosure and possible loss of income (Badgett, 1995).

The potential for discriminatory treatment due to sexual orientation depends on the employers' ability to distinguish gays from other men. Even if employers wish to discriminate against employees who are homosexual, they have few ways to judge these aspects of individuals' lives. An employer could become aware of an employee's sexual orientation if the employee was open about sexuality at work or if he led an openly homosexual lifestyle. In our study, following Adam (1981) and Weichselbaumer (2003), the gay applicants' sexual orientations were labeled by a line in the personal information part of the resume: member volunteer in the Athenian Homosexual Community. ${ }^{9}$ For the straight half of the applicants, no explicit information on sexual orientation was given. In the current experiment, we wanted to investigate whether gay-labeled applicants experienced any type of workplace disadvantage since understanding what it means to be gay is seen by society as incompatible with understanding what it means to be a promising employee (Mason and Palmer, 1996). However, to control for the probability that the volunteer activity might have created a conflict with his present duties, the application documents indicated that those activities had ended. Also, in case that activism might have biased the selection process, the straight men's curriculum vitae mentioned past volunteerism in an environmental community. Moreover, in order to look at the effect of unobservable characteristics, we

\footnotetext{
${ }^{7}$ As defined by the status characteristics theory, a status characteristic is a categorical distinction among people, such as personal attributes or roles, that has attached to it widely held beliefs in the culture that associates greater status and competence with one category of the distinction than with others (Berger et al, 1977).

${ }^{8}$ Following Herek (1990), homosexuality pervades societal customs such as institutional racism and sexism. It operates through a dual process of invisibility and attack. It usually remains culturally invisible; when people who engage in homosexua behaviour or who are identified as homosexual become visible, they are then subject to attack by society.

${ }^{9}$ We suggest that many gays and lesbians reveal their sexual orientation despite the possible negative effects on career advancement and income, since hiding one's sexual preference is likely to cause anxiety and stress (Pharr, 1998; Byrne, 1993).
} 
included items on the resumes to signal that the applicant did not fit a number of stereotypes cited by employers as reasons for reluctance in hiring gay workers. Gay men who violate gender rules face considerable prejudice since their mannerisms are inconsistent with society's expectations about masculinity (Herek, 1994). Hence, our matched applicants had similar hobbies (sports, travel) and personal characteristics (productive, sociable, efficient) that implied similar masculinity.

\subsection{Methodology and application structure}

In the current study in order to measure occupational access discrimination for gay applicants, we fabricated two imaginary workers equal in human-capital who applied to the same job by sending cover letters ${ }^{10}$ and curriculum vitae using different fax devices. ${ }^{11}$ Our experiment was conducted from December 2006 to September 2007 and took place in Athens, the capital of Greece. We applied to vacancies where there was demand for employment of $8 \mathrm{~h}$ a day, 5 days a week. These vacancies were identified through a random sample of advertisements appearing in newspaper websites, and we concentrated on low-skilled jobs, as this group is expected to be at more risk for discrimination (Eurobarometer, 2007). Moreover, since the antidiscrimination legislation may have helped disadvantaged groups of homosexuals more, we focused on groups that could be more at risk of discrimination, namely non-graduates, younger workers and those working in the private sector. In the current study, we investigated different occupations for which a variation in discriminatory behavior across vacancies might exist. The occupations on which we focused covered a large spectrum of work environments: office jobs, industry jobs, café and restaurant services and shop sales. These occupations were chosen because while there were many low skilled vacancies in agriculture, construction, cleaning, and delivery, in most of the latter cases only telephone contact was available. Interestingly, the investigated occupations allowed for further classification in accordance with the nature of the research. It is rather obvious that a key issue that arises when low-skilled gay applicants seek employment is the visibility and invisibility of equality, tolerance and diversity in relation to their sexual orientation in different sectors. Some gay people might choose occupations in which workplace disclosure of sexual orientation is least damaging ${ }^{12}$ (Colgan et al., 2006). Since industry vacancies are perceived as masculine jobs, café-restaurant services and sales vacancies are perceived as gay-friendly jobs, and office vacancies are perceived as the jobs with the highest status, we had a further dimension to take into account.

The qualifications and presentation styles of our two fictitious applicants were matched as closely as possible so that they were identical in all employment-relevant characteristics but sexual orientation (see Appendix A). Each application was designed to convey the same level and type of experience that might make an applicant attractive.

Each of our fictitious applicants/testers was allocated a Greek male distinctive first and last name, a mobile telephone number, and a postal address. ${ }^{13}$ The applicants were 29 years old, unmarried, and had carried out military service in different areas. ${ }^{14}$ Applications showed

\footnotetext{
${ }^{10}$ In order to meet the Greek standards, the use of cover letters was appropriate. In Greece, a short cover letter should describe an applicant's desire for the position.

${ }^{11}$ Fax machines were adjusted so as to provide no information (i.e., fax number, affiliations and codes).

12 Homosexuals tend to be overrepresented in certain sectors. The sectors and occupations chosen in real life offer a more tolerant environment, have specific nondiscrimination policies, are more secure, or offer better pension and health schemes However, choosing a job in order to avoid future discrimination is a typical example of indirect discrimination.

${ }^{13}$ The addresses were chosen in order to indicate the same social class.

${ }^{14}$ In Greece, having served in the military typically boosts a male applicant's probability of being hired. Thus, in order for our two candidates to be as equal as possible, we had to consider this crucial factor.
}

the same level of schooling and job experience. Both applicants had finished high school approximately 12 years before, and both applicants had 9 years of work experience in positions similar to the vacancy they were applying for. In order to avoid detection, the candidates' high schools and previous workplaces were located in different areas within Athens.

The application forms were faxed simultaneously within 1 day of the appearance of the advertisement, and, if the firms were interested in any of the applicants, they could be reached either through postal addresses ${ }^{15}$ or by telephone. ${ }^{16}$ For obvious reasons, the styles of the curriculum vitae and cover letters ${ }^{17}$ were different for each pair. However, in order to control for the possibility that the style of an application could influence an employer's response, the two application form styles were equally allocated between the straight and gay applicants. For the same reason, applications were sent at different times to each vacancy; in half of the cases, the straight application was sent first. Both experimental controls were adjusted in the regression stage. $^{18}$

Whenever employers themselves ${ }^{19}$ called to arrange appointments with the applicants, the two testers asked informal questions regarding monthly wage offers. ${ }^{20}$ However, in order to verify that the testers were alike regarding all characteristics, such as accent, ${ }^{21}$ masculinity, articulation, age and manner of speaking, and that they responded similarly to employers' clarifications or questions, we conducted the following pre-tests: having recorded a tester's pilot rehearsal, considerable numbers of individuals were asked to assess the tester in terms of the relevant issues. The true experiment then began after unanimity had been reached. ${ }^{22}$

In the current study, we used a variety of sample selection criteria to identify the group of wages on which we should focus. Our analysis was limited to those cases where wages were offered to both applicants. By doing this, we gained partial control over idiosyncratic differences in firm evaluations based on common bundles of characteristics that plague ordinary observational studies. Actually, eliminating common unobserved components made it possible to construct better tests of the hypothesis of no discrimination since, in paired offers, the underlying employer distribution was the same. Specifically, a bias was present if the variables that determined whether the applicants receiving a callback were correlated with the unmeasured variables that affected wage offers.

\footnotetext{
${ }^{15}$ However, no firm responded in writing.

${ }^{16}$ In order to avoid inconveniences to the firms, a day before the interview was to take place, the firms were informed about the applicants' inability to continue the process.

${ }_{17}$ Although the cover letters were similar, they were not identical. Pre-tests were conducted in order to ensure that neither of the two cover letters elicited preferences.

${ }^{18}$ For an extensive study on control variables and random events, see Fix and Struyk (1993).

${ }^{19}$ In order to verify that employers were calling, each tester raised the following questions: "am I speaking to the employer?", “are you the employer?", respectively. In all other cases, i.e., when we did not have the chance to converse with employers, no question regarding monthly wages was raised.

${ }^{20}$ It was reasonable to raise this question since the status of the vacancies and applicants with low human capital qualifications allowed for straightforward interactions. For low-status vacancies, employers offer fixed wages as robust bargaining tools, and complicated arrangements based on human capital criteria are infrequent. This was also confirmed by the fact that approximately half of the employers who called back were prone to make informal offers.

${ }^{21}$ Both testers were chosen to have masculine accents, due to the concern that the level of wage discrimination might be greater against gay applicants with effeminate accents.

${ }^{22}$ Although the telephone approach minimised testers' personal impact on the outcome, the usual drawbacks applied (Heckman and Siegelman, 1993). Moreover, given the low level of factual knowledge about which characteristics employers valued, how personal attributes traded off regarding profitability content, and given the heterogeneity among employers in making these assessments, it was not obvious that experimenters possessed the relevant information required to make perfect matches (Heckman and Siegelman, 1993).
} 
Last but not least, in the current study we assumed that the likelihood of employer discrimination against gay men might also vary with characteristics such as the employer's sex. It is of interest to ascertain whether male and female employers discriminated against gays in similar ways because to our best knowledge no comparable studies exist that examine this issue. In an attempt to assess the role of these characteristics, the testers recorded this information when they received callbacks from employers.

\subsection{Research limitations}

The current study focused on the hiring stage and ignored potential discrimination that could arise later on. If gay workers experience losses in earnings because they more frequently end up in dead-end jobs or face glass ceilings, estimates based on starting positions would not pick up these effects. ${ }^{23}$ Hence, correspondence testing can be effective only in demonstrating discrimination at the initial stage of a selection process as well as in measuring the results of the selection process (Bertrand and Mullainathan, 2004). In this context, however, it is important to know whether a candidate will eventually get a job as well as the candidate's earnings upon getting the job. In real life, job offers are also obtained via informal searches and networks. This omission could qualitatively affect our results if gays use social networks more or if employers who rely more on networks differentiate less by sexual orientation ${ }^{24}$ (Bertrand and Mullainathan, 2004).

Moreover, a basic selection problem arose, in that the analysed sample consisted of observations for those cases where both applicants received wage offers. This sample may differ in important unmeasured ways from samples where only one applicant received a wage offer. Hence, information was not taken from the entire population; rather, the population was limited by including individuals where both applicants were invited for interviews and both received wage offers.

Finally, we must note that all the inferences that we have drawn about wage differences were subject to serious concerns about the quality of the data. To the extent that employers only imperfectly observed the sexual orientation of the applicants, any evidence of discrimination that we found represented an understatement of the extent of discrimination against gays. Moreover, it is of course impossible to test a firm's truthfulness until a candidate is actually hired.

\section{The model}

The most common econometric approach for capturing the effects of discrimination is to ask if people who are similar in all observable and economically relevant ways have similar labour market outcomes. The probability of receiving a job interview was estimated according to a Probit model:

$Y_{i}^{*}($ Callback $=1)=\alpha+\beta X_{i}+e_{i 1}$,

where: $Y^{*}$ is the latent variable reflecting the probability of receiving a job interview, $\alpha$ is a constant, $X$ refers to sexual orientation, which equals one (zero) if the respondent was labeled as being gay (in all other cases), $e$ is the disturbance, and $i$ refers to the individual. In correspondence testing (see Neumark et al., 1996; Bertrand and Mullainathan, 2004; Carlsson and Rooth, 2007), all applicants must be matched in all characteristics other than sexual orientation. Having controlled for all characteristics except sexual orientation across the two applicants, the latter were not expected to be correlated with the error term in each equation. If $\widehat{\beta}=0$, the gay and heterosexual applicants had the same probability of receiving a job interview. If $\widehat{\beta}<0$, the gay applicant had a lower probability than the heterosexual of receiving a job interview, while if $\widehat{\beta}>0$, the gay applicant had a higher probability than the heterosexual of receiving a job interview.

Eq. (1) was estimated simultaneously for all types of jobs for each type of applicant, and we report marginal effects. ${ }^{25}$ For completeness, three models were estimated. The first model controlled only for differences in sexual orientation between applicants, application type (A or B) and sending order. The second model controlled also for occupation applied too (four dummies). The third model controlled also for common time effects (ten dummies). As applications were sent over a period of 10 months, it was necessary to control for common time effects via time dummies, defined according to the date of application submission (see Petit, 2007).

Moreover, to estimate the effect of sexual orientation on the wage offered, we used straightforward OLS log regressions. ${ }^{26}$ A Mincer-type equation relating to employers' monthly wage offers according to a sexual orientation indicator was estimated (see Badgett, 1995; Black et al., 2003; Carpenter, 2005). The key variable of interest was a dummy variable indicating that the applicant was gay. The dependent variable was derived from employers' responses to the question "what is the monthly wage you offer for the vacancy?". 27 The relevant econometric model can be given by:

$\log ($ monthly wage offers $)=\alpha+\beta X_{i}+e_{i 2}$,

where, similarly to Eq. (1), $X$ is an indicator variable equal to one (zero) if the respondent is labeled as gay (in all other cases). The main effect of discrimination, if any, will be captured by the sexual orientation coefficient. A statistically significant negative coefficient would imply discrimination in the form of lower wages. Similarly, Eq. (2) was estimated simultaneously for all types of jobs for each type of applicant. Hence, a vector of indicator variables for type of curriculum vitae, $^{28}$ employees' callback order, ${ }^{29}$ occupation dummies, and time effect dummies was included in the Eq. (2).

Regarding the second relationship, wage offers were of course observed only if an applicant received a callback. Under this structure, we assumed that sexual orientation presumably influenced informal wage offers. Actually, we did not have a vector of factors known to influence invitations for interview and wage offers other than sexual orientation. Thus, Heckman selection models could not be estimated. However, what really mattered in this experiment was the intra-class correlation. Regarding the first relationship, two applications were sent to the same firm; hence, the probability of the heterosexual applicant receiving a callback was correlated with the probability of the gay applicant receiving one. Moreover, in the second relationship, wage offers were expected to be correlated for the two applicants. In order to correctly analyse the data, those correlations needed to be

\footnotetext{
25 Since the explanatory variable was a dummy variable, its marginal Probit reported the discrete change in the probability of an interview offer, $\partial p r o b($ Callback $=1) / \partial X_{i}$.

${ }^{26}$ The wage is included in its natural logarithmic form so that the resulting estimated coefficients are more easily interpretable as percentages.

27 Or alternatively, "Can you inform me of the monthly wage you offer?".

${ }^{28}$ Wage offers could be affected by the applicants' curriculum vitae type; thus, we had to incorporate this effect.

${ }^{29}$ In each callback, the employers were asked to give wage offers. Hence, the offers for the two applicants could be affected by the callback order.
} 
Table 1

Aggregate correspondence test results.

\begin{tabular}{|c|c|c|c|c|c|c|c|c|c|}
\hline \multirow{3}{*}{$\frac{\text { Outcomes }}{\text { Occupations }}$} & \multirow[t]{2}{*}{ Jobs } & \multirow{2}{*}{$\begin{array}{l}\text { Neither } \\
\text { invited }\end{array}$} & \multirow{2}{*}{$\begin{array}{l}\text { At least } \\
\text { one invited (1) }\end{array}$} & \multirow{2}{*}{$\begin{array}{l}\text { Equal } \\
\text { treatment }\end{array}$} & \multirow{2}{*}{$\begin{array}{l}\text { Discrimination } \\
\text { against gays (2) }\end{array}$} & \multirow{2}{*}{$\begin{array}{l}\text { Discrimination } \\
\text { against straights (3) }\end{array}$} & \multicolumn{2}{|c|}{ Net discrimination } & \multirow[t]{3}{*}{$x^{2}$ test } \\
\hline & & & & & & & $(2)-(3)$ & {$[(2)-(3)] /(1)$} & \\
\hline & No. & No. & No. & No. & No. & No. & $\overline{\text { No. }}$ & $\overline{\%}$ & \\
\hline Office jobs & 455 & 268 & 187 & 46 & 140 & 1 & 139 & 74.3 & $137.02 *$ \\
\hline Industrial jobs & 346 & 215 & 131 & 40 & 89 & 2 & 87 & 66.4 & $83.17 *$ \\
\hline Restaurant and café services & 511 & 342 & 169 & 57 & 110 & 2 & 108 & 63.9 & $104.14 *$ \\
\hline Shop sales & 402 & 193 & 209 & 87 & 118 & 4 & 114 & 54.5 & $106.52 *$ \\
\hline Total & 1714 & 1018 & 696 & 230 & 457 & 9 & 448 & 64.3 & $430.69 *$ \\
\hline
\end{tabular}

Notes: The null hypothesis is that "both individuals are treated unfavourably equally often," that is (2)=(3). *Statistically significant at the $1 \%$ level.

taken into account. In the estimations that follow, full informationadjusted standard errors were therefore reported.

\section{Results}

\subsection{Descriptive statistics}

Following Riach and Rich (2002), we provide the full details of our field experiment. This includes the procedure adopted and the complete results of all tests, broken down by occupational category. The primary question we asked was, "What constitutes an outcome that exhibits discrimination?" In a study of majority/minority employment opportunities, an intuitively plausible measure of (the existence of) discrimination is the proportion of times that the two applicants were treated differently by potential employers. Complete results thus necessitate recording when both were rejected or invited and when only the majority or minority applicant was invited to interview. The outcome of our correspondence testing was thus first set out in a format that followed McIntosh and Smith (1974), which has since been adopted in field experiments across Europe (Riach and Rich, 2002).

In Table 1, the last row shows the aggregated results, and, from the second column, it can be seen that applications were sent to 1714 job openings. The third column shows that, in 1018 cases, neither individual was invited for interview. In the remaining 696 cases (column four), at least one applicant was invited. In 230 cases (column five), both were invited (equal treatments), in 457 cases (column six), only the straight applicant was invited, and, in 9 cases (column seven), only the gay person was invited. Hence, net discrimination ${ }^{30}$ against the gay applicant can be read from the last two columns and is 448 cases, or $64.3 \%$. The statistical significance of any finding of net discrimination was determined using the chi-squared test (Heckman and Siegelman, 1993). In all sectors, the outcomes were significant at the $1 \%$ level. This form of direct discrimination resulted in equally productive individuals being treated differently. However, these differentials were observed after the antidiscrimination legislation was enacted, and it is impossible to conclude whether the legislation had much effect on these outcomes.

Although applicants were designed to appear similar, they looked different to employers. The findings revealed significant differences for the two counterpairs across all sectors, suggesting that, regardless of the status of the vacancies, discrimination was widespread, with the straight applicants always having an advantage. In all low-skill occupations, the gay applicants were found to face significant constraints in the selection process. In particular, gay applicants were faced with the highest occupational access constraints for office jobs, which constitute a

\footnotetext{
${ }^{30}$ The most common way to measure the overall incidence of discrimination is to count the numbers of times a minority applicant was treated less favourably on a single type of firm behaviour than the majority applicant and then to subtract the number of times the majority applicant was treated less favourably, mainly in random incidents. The result is a net measure of the number of acts of discrimination a minority applicant can expect to encounter during each application to a firm.
}

higher-status sector. Interestingly, and parallel to the above analysis, gay applicants did not seem to enjoy an access premium in gay-friendly occupations. Although the discrimination factor reached its lowest values in shop sales and restaurant and café vacancies, the net discrimination was not significant compared to industrial and office jobs. $^{31}$

Table 2 presents the mean values of the logarithm of informal wage offers on the part of employers. Panel (1) presents the extended sample. Our sample contained 110 paired offers, 88 coming from male employers and 22 from female employers. While gays had levels of education and experience similar to those of their heterosexual counterparts, the data suggest that gay applicants were offered informal wages lower than heterosexual applicants (6.497 versus 6.512). This might be due to a disclosure effect. For completeness, we report sample means separately for male and female employers. Panel (2) shows that male employers offered the gay applicants' wages lower than those offered to straight applicants (6.486 versus 6.499). Panel (3) presents a similar trend for female employers (6.496 versus 6.517). On this basis, it seems that sexual orientation has a small effect on observable outcomes.

\subsection{Estimations}

Table 3, presents the key results from our callback regressions. All of these regressions included controls for sending order and type of curriculum vitae. Individual regressions with and without occupation and time effect controls were also estimated. Column (1) shows that the estimated probability of gay applicants receiving an invitation for an interview was lower by $26.2 \%$ than for heterosexuals. In the regression presented in column (2), we have also included four occupation dummies; however, the estimations did not vary; the estimated effect changed from $26.2 \%$ to $26.5 \%$. Moreover, column (3) presents estimates obtained when adding ten additional dummies to control for each month. The point estimate on sexual orientation dropped from $26.5 \%$ to $23 \%$. In all cases, the results were statistically significant at the $1 \%$ level.

The current study revealed clear differences between straight and gay applicants. The findings provided significant evidence that, when two identical applicants engaged in an identical job search, the gay applicant would receive fewer interview callbacks. This result implies that gay men are discriminated against when actual employers make hiring decisions. Furthermore, it seems that gay men have to spend more time, effort, and resources than straight men to obtain an interview, as the same observable signal was more precise for straights than for gays. Hence, it seems that employers implicitly expect more competent performance from those with the more valued state of the sexual orientation characteristic, i.e., straights,

\footnotetext{
${ }^{31}$ Hence, although sexual minority individuals may want to segregate in gay-friendly sectors, our results do not support this ability. Greek firms seemed to be reluctant whenever they had to interact with gay applicants. Both gay-friendly firms and gay entrepreneurship in Greece are scarce, in concordance with the general homophobic trends in society.
} 
Table 2

Mean natural logarithm of wage offers.

\begin{tabular}{|c|c|c|c|c|c|c|}
\hline \multirow[t]{3}{*}{ Occupations } & \multicolumn{2}{|c|}{ Entire sample } & \multicolumn{2}{|c|}{ Male employers } & \multicolumn{2}{|c|}{ Female employers } \\
\hline & \multicolumn{2}{|l|}{ (1) } & \multicolumn{2}{|l|}{$\overline{(2)}$} & \multicolumn{2}{|l|}{ (3) } \\
\hline & Straights & Gays & Straights & Gays & Straights & Gays \\
\hline Office jobs & 6.616 & 6.607 & 6.596 & 6.583 & 6.640 & 6.617 \\
\hline Industrial jobs & 6.541 & 6.529 & 6.530 & 6.519 & 6.548 & 6.559 \\
\hline Restaurant and café services & 6.486 & 6.466 & 6.497 & 6.467 & 6.393 & 6.305 \\
\hline Shop sales & 6.456 & 6.436 & 6.446 & 6.440 & 6.439 & 6.426 \\
\hline Total & 6.512 & 6.497 & 6.499 & 6.486 & 6.517 & 6.496 \\
\hline$N$ & 110 & 110 & 88 & 88 & 22 & 22 \\
\hline
\end{tabular}

Table 3

Probit estimations, marginal effects.

\begin{tabular}{|c|c|c|c|}
\hline & \multicolumn{3}{|l|}{ Controls: } \\
\hline & $\mathrm{CV}$ sending order and type & Add occupations & Add months \\
\hline & $(1)$ & $\overline{(2)}$ & $\overline{(3)}$ \\
\hline Sexual orientation & $-0.262 *(0.018)$ & $-0.265^{*}(0.020)$ & $-0.230 *(0.019)$ \\
\hline$R$-squared & 0.077 & 0.092 & 0.455 \\
\hline$N$ & 3428 & 3428 & 3428 \\
\hline
\end{tabular}

Notes: Each column is a separate regression. Standard errors are in parentheses. *Statistically significant at the $1 \%$ level.

compared with those with the less valued state, i.e., gays (Correll and Ridgeway, 2003). Thus, the outcomes suggest that gay men are more likely to be unemployed than heterosexuals since we assumed that an applicant received an interview only if he had a substantial chance of getting the job.

Moreover, we explored differences in responses to gay applicants by employer gender. ${ }^{32}$ The coefficients reported in Table 4 show the estimated callback effect for the gay applicants based on employers' genders. ${ }^{33}$ We found that gay applicants faced a $34.8 \%$ lower chance of being invited for an interview if the employer was male (column 1). Adding more controls, we estimated that the effect was in excess of $1.5 \%$ (columns 2 and 3 ), and all results were significant at the $1 \%$ level. Hence, the disadvantage held after controlling for occupation and time effects. Following Kimmel (1994) and Kimmel and Mahler (2003), sexual orientation discrimination is not evenly distributed throughout society; it is more or less pronounced according to demographic characteristics. ${ }^{34}$ Consistent with empirical evidence, we found that males discriminate more than females. It seems that male employers were more reluctant in their reactions to homosexuality as they were significantly more prone to practice higher occupational access discrimination than

\footnotetext{
32 Notice that discriminatory treatments against heterosexual candidates were generally attributed to random events. Following Wienk et al (1979), the share of calls in which a minority candidate was favoured provided an estimate of the extent to which random factors were at work. In our case, the occupational access discrimination against straight applicants was a negligible outcome; thus, we were unable to test for any correlation between employers' gender and potential discrimination against the straight applicant.

${ }^{33}$ The effect of employers' gender in gays' callbacks was estimated as a Probit model. The dependent variable was the probability that the gay applicant was invited for an interview. The independent variable was a dummy variable that indicated employers' gender, which equals one (zero) if the employer was female (in all other cases).

${ }^{34}$ A sizeable number of empirical surveys show individuals' attitudes toward gaylabeled men to be consistently correlated with gender (Yang, 1997). According to Herek (1986), males' relationship between homophobia and masculinity is evident in their relatively stronger allegiance to homophobic attitudes. However, we must keep in mind that a complete understanding of discrimination against gay men requires an analysis of its roots in culture and social interactions, as well as individual thought processes. People's attitudes are definitely formed on the basis of personal experiences, beliefs, norms and standards as well as on actual contextual events (Herek, 1992, 2000; Pharr, 1998)
}

Table 4

Probit estimations for the gay-labeled applicants, marginal effects.

\begin{tabular}{|c|c|c|c|}
\hline & \multicolumn{3}{|l|}{ Controls: } \\
\hline & CV sending order and type & Add occupations & Add months \\
\hline & $\overline{(1)}$ & $\overline{(2)}$ & (3) \\
\hline Employers' gender & $-0.348 *(0.021)$ & $-0.363 *(0.043)$ & $-0.363 *(0.045)$ \\
\hline$R$-squared & 0.036 & 0.055 & 0.163 \\
\hline$N$ & 696 & 696 & 696 \\
\hline
\end{tabular}

Notes: Each column is a separate regression. Standard errors are in parentheses. *Statistically significant at the $1 \%$ level.

Table 5

Monthly wages differentials, OLS.

\begin{tabular}{|c|c|c|c|}
\hline & \multicolumn{3}{|l|}{ Controls: } \\
\hline & Callback order and CV type & Add occupations & Add months \\
\hline & $(1)$ & $(2)$ & (3) \\
\hline Sexual orientation & $-0.016(0.011)$ & $-0.016(0.009)$ & $-0.016(0.013)$ \\
\hline$R$-squared & 0.013 & 0.222 & 0.325 \\
\hline$N$ & 220 & 220 & 220 \\
\hline
\end{tabular}

Notes: Each column is a separate regression. Standard errors are in parentheses. The dependent variable is the natural logarithm of average monthly wage offers. *Statistically significant at the $1 \%$ level; **at the $5 \%$ level.

females. Greek males might hold stronger beliefs than females about gender and morality; men might define homosexuality as "inferior", which predetermines their attitudes.

Table 5 presents the OLS wage coefficients. As shown in column 1 , the negative effect of gays' sexual orientation was -0.016 (i.e. $1.6 \%$ ) and statistically insignificant. The lower accessibility of gays relative to that of straights to the reference occupations entailed discriminatory, but statistically insignificant, effects in the ensuing steps of the selection process. If we added more controls, we continued to find that gay men faced the same estimated earnings effect of homosexuality. It might appear that our results established that there was no significant relationship between informal wage offers and sexual orientation. While one might argue than a $1.6 \%$ difference in earnings between gay and heterosexual men is still economically important, the current findings of no significant differentials do not imply that differentials do not exist elsewhere in the labour market.

In Table 6, we report the effect of employers' gender on the informal wage offers. ${ }^{35}$ The estimated earnings effect of being gay changed from -0.009 when the employer was male to about -0.013 when the employer was female (columns 1 and 4). For gays, the wage penalty was stronger if the employers were women. However, all the results were statistically insignificant. In columns (2)-(3) and (5)(6), we report results for regressions in which we included further controls. Although the penalty became more negative, we found no discernable changes in any of these gaps after controlling for occupation and time effects.

\section{Discussion}

These results establish that the relationships between sexual orientation and access constraints are the consequence of discrimination, whereby gay men face poorer market hiring prospects than their heterosexual counterparts. However, we found little evidence that gay men face different informal wage offers from

\footnotetext{
35 The effect of employers' gender in applicants' wages was estimated using OLS regressions per gender. The dependent variable was log wages. The independent variable was a dummy variable, which indicated applicants' sexual orientation.
} 
Table 6

Monthly Wages Differentials, OLS.

\begin{tabular}{|c|c|c|c|c|c|c|}
\hline & Male employers & & & Female employers & & \\
\hline & Controls & & & Controls & & \\
\hline & Callback order and CV type & Add occupations & Add months & Callback order and CV type & Add occupations & Add months \\
\hline & $\overline{(1)}$ & $(2)$ & (3) & $\overline{(4)}$ & $\overline{(5)}$ & $(6)$ \\
\hline Sexual orientation & $-0.009(0.006)$ & $-0.009(0.008)$ & $-0.010(0.012)$ & $-0.013(0.012)$ & $-0.017(0.009)$ & $-0.019(0.011)$ \\
\hline$R$-squared & 0.026 & 0.166 & 0.314 & 0.077 & 0.597 & 0.671 \\
\hline$N$ & 176 & 176 & 176 & 44 & 44 & 44 \\
\hline
\end{tabular}

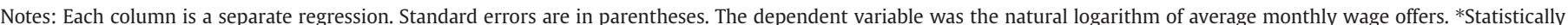
significant at the $1 \%$ level; **at the $5 \%$ level.

employers than heterosexual men. A number of important issues concerning the interpretation of these results should be noted. Because discrimination resulted in two equally qualified individuals being treated differently, discrimination is also against the interest of equality. Hence, it is interesting to ask how previously proposed theories explain the observed effects associated with sexual orientation. In this section, we briefly review the two main strands of the theoretical literature on discrimination in the context of sexual orientation. These are distaste for the minority (Becker, 1957) and statistical discrimination (Arrow, 1973; Phelps, 1972; Aigner and Cain, 1977).

With respect to the first effect, lower occupational access for gay men than for straight men, the basic story of Becker's discrimination suggests that sexual minority individuals can potentially face occupational access discrimination. If employers, co-workers and/or consumers have tendencies towards discrimination and can distinguish gay employees from heterosexuals, the result may be discriminatory treatments. This tendency translates into a monetary offer or demand function for an attribute such as sexual orientation. In particular, employers, consumers or employees are willing to pay a higher wage or price or receive a lower wage in order to associate with people with specific attributes.

As demonstrated by Heckman (1998), the correspondence testing does not exclusively identify the extent of taste discrimination. Observed discrimination can also occur if employers use group information when evaluating applicants; i.e., statistical discrimination can be at play. If employers believe that there is a systematic differential between the gay and heterosexual applicants in their reliability aptitude and job stability, this is sufficient to create a permanent differential in access availability and/or wages. In this situation, discrimination is not the consequence of exogenous preferences but of profit-maximizing behavior of risk-averse employers. Consequently, citing either employer distaste and/or employer perception that being gay signals lower productivity, gays receive substantially fewer callbacks for each resume that they send out.

On the other hand, the second effect, the lack of wage offer discrimination on the part of employers, is generally inconsistent with employers' tastes and statistical assumptions against gay men. The patterns of results found here appears inconsistent with the findings of previous studies (Badgett, 1995; Carpenter, 2007). The expected large wage penalties against gay men were not confirmed. Notably, the size of the estimated reduction in income associated with homosexuality fell within the range of the most recent studies in the Netherlands (Plug and Berkhout, 2004) and California (Carpenter, 2007). As Carpenter (2005) notes, the findings of the previous studies are somewhat sensitive to the time period considered. However, in our experiment, we must be cautious in drawing this reference. Because of the data selection and the experimental methodology, wage estimations were probably biased. Since these employers invited gay applicants for interviews, this could be a sign that they were not prone to practice any discriminatory treatment (including wage discrimination) against them in case of tentative hiring. Hence, this result might not accurately characterize the potential wage gap that employed gay men face in the private Greek labour market.

A better understanding of the nature of sexual orientation is essential both to derive policies from this analysis and to correctly specify the empirical models. The former evidence suggests that discrimination continues at alarming levels, and it suggests the need to more closely examine the effects of sexual orientation discrimination and labour market characteristics on employment for gay workers in Greece.

\section{Conclusions}

A noticeable increase in social science research focusing on gay men and lesbians has occurred over the last decade. However, the existing literature on sexual orientation has ignored Greece. To investigate whether discrimination against gay men exists, a correspondence test was conducted. In this survey, we isolated and experimentally evaluated the taste and statistical discrimination hypotheses that are have been proposed to explain some of the disadvantages gay applicants experience in the private labour market. Focusing on the selection process and experimentally holding the human capital of a pair of fictitious job applicants constant and varying only their sexual orientation, our results revealed significant differences in access to occupations, while differences in wages offered against gay applicants were insignificant. These results prove that a history of discrimination could not be turned around overnight. Despite measures to encourage openness and discourage discrimination in the European Union, serious misconceptions and barriers are encountered by sexual minority individuals in the Greek job market.

\section{Appendix A. Curriculum vitae types - short versions}

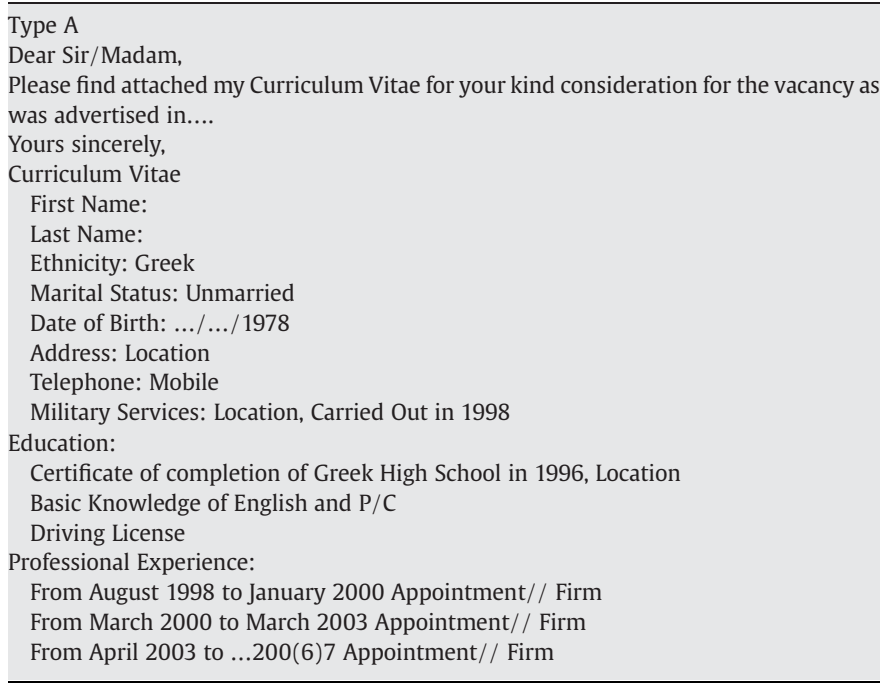

(continued on next page) 


\section{Appendix A (continued)}

Type A

Interests: Sports and Trave

Member volunteer in the Athenian Homosexual Community (01-05)

Personal Characteristics: Productive and sociable

Type B

Dear Sir/Madam,

Please consider my application for the vacancy as was advertised in.... I attached my curriculum vitae.

Yours faithfully,

Curriculum Vitae

First Name

Last Name

Date of Birth .../.../1978

Ethnicity Greek

Marital Status Unmarried

Address Location

Telephone Mobile

Experience

Appointment/Firm

February1998-November1999

Appointment/Firm

December1999-July 2004

Appointment/Firm

August2004-...200(6)7

Education

Certificate of completion of Greek High School in 1996, Location

English Basic Knowledge

$\mathrm{P} / \mathrm{C}$ Basic Knowledge

Personal

Military Services Carried Out in 1998

Hobbies Volunteer in the Olympus: Environmental Union from 1999-2003, Travel/ Sports

Personality Industrious, Efficient, sociable

Driving License

\section{References}

Adam, B., 1981. Stigma and employability: discrimination by sex and sexual orientation in the Ontario legal profession. Canadian Review of Sociology and Anthropology 18 (2), 216-222.

Aigner, D., Cain, C. 1977. Statistical theories of discrimination. In: Ashenfelter, O., Rees, A (Eds.), Discrimination in the Labor Markets. Princeton University Press.

Allegretto, S., Arthur, M., 2001. An empirical analysis of homosexual/heterosexual male earnings differentials: unmarried and unequal? Industrial and Labour Relation Reviews 54 (3), 631-646.

Arabsheibani, G.R., Marin, A., Wadsworth, J., 2004. Gay pay in the UK. Economica 72 (286), 333-347.

Arrow, K.J., 1973. The theory of discrimination. In: Ashenfelter, O., Rees, A. (Eds.), Discrimination in Labour Markets. Princeton: Princeton University Press, pp. 3-33.

Badgett, M.V.L., 1995. The wage effects of sexual orientation discrimination. Industrial and Labour Relations Review 48 (4), 726-739.

Becker, G.S., 1957. The Economics of Discrimination. University of Chicago Press, Chicago.

Becker, G.S., 1991. A Treatise on the Family. Harvard University Press, Cambridge, Mass.

Becker, G.S., 1993. Human Capital. University of Chicago Press, Chicago.

Berg, N., Donald, L., 2002. Measuring the effect of sexual orientation on income: evidence of discrimination. Contemporary Economic Policy 20 (4), 394-414.

Berger, J., Hamit, M.F., Norman, R.Z., Zelditch Jr., M., 1977. Status Characteristics and Social Interaction: An Expectation States Approach. Elsevier, New York.

Bertrand, M., Mullainathan, S., 2004. Are Emily and Greg more employable than Lakisha and Jamal? Field experiment on labour discrimination. American Economic Review 991-1014.

Black, D.A., Hoda, R.M., Seth, S., Lower, T., 2003. The earnings effects of sexual orientation. Industrial and Labor Relations Review 56 (3), 449-469.

Blandford, J.M., 2003. The nexus of sexual orientation and gender in the determination of earnings. Industrial and Labor Relations Review 56 (4), 622-642.

Byrne, J., 1993. Affirmative action for lesbians and gay men: a proposal for true equality of opportunity and workforce diversity. Yale Law and Policy Review (11), 47-56.

Carlsson, M., Rooth, D.O., 2007. Evidence of ethnic discrimination in the Swedish labour market using experimental data. Labour Economics 14 (4), 716-729.

Carpenter, C.S., 2005. Self-reported sexual orientation and earnings: evidence from California. Industrial and Labor Relations Review 58 (2), 258-273.

Carpenter, C.S., 2007. Revisiting the income penalty for behaviorally gay men: evidence from NHANES III. Labour Economics (14), 25-34.
Clain, S., Leppel, K., 2001. An investigation into sexual orientation discrimination as an explanation for wage differences. Applied Economics 33, 37-47.

Colgan, F., Creegan, C., McKearney, A., Wright, T., 2006. Lesbian, gay and bisexua workers: equality, diversity and inclusion in the workplace. A Qualitative Research Study. Comparative Organization and Equality Research Centre, London, Metropolitan University.

Correll, J.S., Ridgeway, C.L., 2003. Expectations states theory. In: Delamater, J. (Ed.), Handbook of Social Psychology. Kluwer Academic Press, New York, pp. 29-51.

De Schutter, O., 2008. Homophobia and Discrimination on Grounds of Sexual Orientation in the EU Members States: Part I, Legal Analysis. European Union Agency for Fundamental Rights.

Fix, M., Struyk, R., 1993. Clear and Convincing Evidence: Measurement of Discrimination in America. The Urban Institute Press, Washington, D.C.

Heckman, J.J., 1998. Detecting discrimination. Journal of Economic Perspectives 12, 101-116.

Heckman, J., Siegelman, P., 1993. The urban institute audit studies: their methods and findings. In: Fix, M., Struyk, R. (Eds.), Clear and Convincing Evidence: Measurement of Discrimination in America. Urban Institute Press, Washington, DC.

Herek, G.M., 1986. On heterosexual masculinity. American Behavioural Scientist 27, 545-562.

Herek, G.M., 1990. The context of anti-gay violence: notes on cultural and psychological heterosexism. Journal of Interpersonal Violence 5, 316-333.

Herek, G.M., 1992. Psychological heterosexism and anti-gay-labeled-labeled violence: the social psychology of bigotry and bashings. In: Herk, G.M., Berrill, K.T. (Eds.) Hate Crimes: Confronting Violence Against Lesbians and Gay Men. Sage, Thousands Oaks, CA.

Herek, G.M., 1994. Assessing attitudes toward lesbians and gay men: a review of empirical research with the ATLG Scale. In: Greene, B., Herek, G.M. (Eds.), Lesbians and Gay Psychology. Sage, Thousands Oaks, CA

Herek, G.M., 2000. The psychology of sexual prejudice. Current Directions in Psychological Science 9, 19-22.

Kimmel, M., 1994. Masculinity as homophobia: fear, shame and silence in the construction of gender identity. In: Brod, H., Kaufman, M. (Eds.), Theorizing Masculinities. Sage, Newbury Park, CA, pp. 119-141.

Kimmel, M.S., Mahler, M., 2003. Adolescent masculinity, homophobia, and violence: random school shootings, 1982-2001. American Behavioral Scientist, vol. 46 No. 10. State University of New York at Stony Brook, pp. 1439-1458. June 2003.

Levine, M., Leonard, R., 1984. Discrimination against lesbians in the work force. Signs 9 (4), 700-710

Mason, A., Palmer, A., 1996. Queer Bashing: A National Survey of Hate Crimes Against Lesbians and Gay Men. Stonewall, London.

McIntosh, N., Smith, D., 1974. The Extent of Racial Discrimination, Political and Economic Planning Broadsheet no. 547. Political and Economic Planning London.

Neumark, D., Bank, R.J., Van Nort, K.D., 1996. Sex discrimination in restaurant hiring: an audit study. Quarterly Journal of Economics 111 (3), 915-941.

Peponas, M., 2004. Combating sexual orientation discrimination in employment. Report of the European Group of Experts on Combating Sexual Orientation Discrimination about the Implementation up to April 2004 of Directive 2000/78/EC Establishing a General Framework for Equal Treatment in Employment and Occupation, Chapter 9 , pp. 229-246.

Petit, P., 2007. The effect of age and family constraints on gender hiring discrimination: a field experiment in the french financial sector. Labour Economics 14, 371-391.

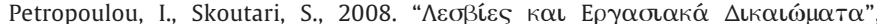

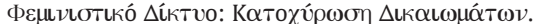

Pharr, S., 1998. Homophobia: A Weapon of Sexism. Chardon Press, Little Rock.

Phelps, E.S., 1972. The statistical theory of racism and sexism. American Economic Review 659-661.

Plug, E., Berkhout, P., 2004. Effects of sexual preferences on earnings in the Netherlands. Journal of Population Economics 17 (1), 117-131.

Riach, P.A., Rich, J., 2002. Field experiments of discrimination in the market place. The Economic Journal 112, F480-F518.

Seidman, S., 1994. Queer-ing sociology, sociologizing queer theory: an introduction. Sociological Theory 12 (2), 166-177.

Special Eurobarometer, 2007. Discrimination in the European Union. Wave 26365.4

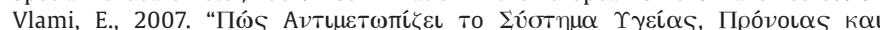

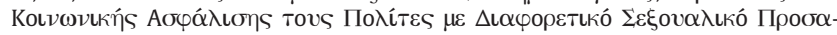

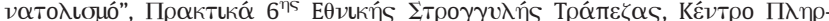

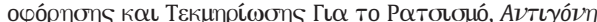

Weichselbaumer, D., 2003. Sexual orientation discrimination in hiring. Labour Economics 10, 629-642.

Weinberg, G., 1972. Society and the Healthy Homosexual. St. Martin's, New York.

Wienk, R., Reid, C., Simonson, J., Eggers, F., 1979. Measuring Racial Discrimination in American Housing Markets: The Housing Market Practices Survey, Office of Policy Development and Research, Washington DC: U.S. Department of Housing, Urban Development.

Yang, A.S., 1997. Trends attitudes toward homosexuality. Public Opinion Quartely 61 $477-500$ 